\title{
Effective Viscosity of Slag and Kinetic Stirring Parameter Applied in Steel Cleanliness During Vacuum Degassing
}

\author{
Vinicius Cardoso da Rocha ${ }^{a}$, Julio Aníbal Morales Pereira ${ }^{a}$, Ayumi Yoshioka ${ }^{b}$, Wagner Viana \\ Bielefeldt ${ }^{a}$, Antônio Cezar Faria Vilela ${ }^{a}$ \\ ${ }^{a}$ Ironmaking and Steelmaking Laboratory (LaSid), Federal University of Rio Grande do \\ Sul, Porto Alegre, RS, Brazil. \\ ${ }^{b}$ Gerdau Technical Advisor in Research and Development, Charqueadas, RS, Brazil.
}

Received: February 09, 2017; Revised: June 21, 2017; Accepted: July 21, 2017

\begin{abstract}
The process of vacuum degassing occurs during the secondary refining of special steels. Its main function is to remove undesirable gases. However, during this process, flotation phenomenon and inclusions absorption are reported. The aim of the present work was to study the slag viscosity and vacuum degassing (tank type) capacity in steel cleanliness from an industry perspective. To achieve this objective, slag and steel samples were taken before and after the vacuum stage. The results in steel cleanliness were related to a kinetic stirring parameter $\left(\beta_{s}\right)$ of the vacuum station and to the effect of slag viscosity. The removal of inclusions during the vacuum stage reached 64,75 and $78 \%$ in the diameter ranges of 2.5-5, 5-15 and $\geq 15 \mu \mathrm{m}$, respectively. After the degassing process, the composition of non-metallic inclusions seemed to approach the slags' chemical compositions. The stirring process in the vacuum degassing station promotes a significant decrease in the inclusion densities for the 2.5-15 $\mu \mathrm{m}$ diameter range and also in the sulfur content in liquid steel. Regarding the effective viscosities of slags, it was concluded that lower values (0.20 Pa.s) increased slag capacity in inclusion removal, whereas higher values (>0.40 Pa.s) were detrimental to steel cleanliness.
\end{abstract}

Keywords: Slags, vacuum degassing, steelmaking, steel cleanliness, inclusion removal.

\section{Introduction}

In recent decades, the steel industry has been subjected to a large effort aimed at obtaining high quality steels. Vacuum degassing constitutes a crucial stage in the steelmaking process ${ }^{1}$. At the end of this stage, deoxidation, desulphurization, inclusion and gas removal must be achieved ${ }^{2,3}$. During ladle treatment, a vacuum degassing station is an important unit process for removal and control of several detrimental impurities ${ }^{4}$. One of these impurities is known as non-metallic inclusions. Non-metallic inclusions represent a parameter related to steel cleanliness, including their composition, size and distribution ${ }^{5}$. According to Riyahimalayeri, Ölund and Selleby $^{2}$ vacuum degassing should remove the unwanted non-metallic inclusions as much as possible, resulting in a cleaner and more homogeneous steel melt. These unwanted inclusions are related to its destructive effect on the fatigue properties of some steels.

Recently, with regards to the increasing demand of cleaner steels, some research ${ }^{1,2,6-12}$ was performed in the analysis of the vacuum degassing process in steel cleanliness. Specifically, Capurro, Cerrutti and Cicutti ${ }^{6}$ and Capurro et al. ${ }^{7}$ evaluated the effect of the stirring process associated to a kinetic parameter on the steel cleanliness during vacuum treatment. These authors ${ }^{6,7}$ linked this parameter to the inclusion population in the steel bath, regarding density and chemical composition of non-metallic inclusions. Also, these works briefly present an approach regarding the thermodynamics of slags, pointing out the viscosity and driving force of slags in relation to inclusion removal. Some studies ${ }^{13-15}$ have been developed focusing on the thermodynamic analysis of slags, showing the capacity of slag in the removal of inclusions also as a pertinent topic in the search for steels of better quality. In this context, computational thermodynamics has gained application. In the field of inclusions engineering, the application of such thermodynamic software has become fundamental for the study of slag and the inclusionary cleaning of special steels ${ }^{16}$. In fact, computational thermodynamics has been shown to be an excellent tool for the understanding of physicochemical phenomena that occur during the production of steels, also aiding in the decisions to be taken in industrial plants ${ }^{17}$. The study of inclusionary cleanliness of steels in an industrial environment is an arduous task, considering the great amount of incontrollable factors. Most studies related to steel cleanliness are developed on a laboratory scale, 
where the controllable factors are well fixed and, thus, the source of noise can be eliminated. Works developed on the industrial scale are poorly presented in the literature. In this context, the present study, developed in partnership with an industrial plant, becomes relevant because it can gather important results regarding the vacuum process and the removal of inclusions in liquid steel.

The aim of the present work was to study steel cleanliness during the vacuum degassing process. Therefore, samples were taken before and after vacuum treatments in a steelmaking plant. In order to clarify the effect of some parameters of the vacuum degassing process on the inclusion removal, an approach was taken whereby population and chemical composition of inclusions were related to the effective viscosity of slag and a kinetic stirring parameter. The slag viscosity analysis was performed using computational thermodynamics tool.

\section{Materials and Methodology}

In order to evaluate the influence of effective viscosity of slags and the stirring energy promoted by an inert gas through a porous plug, steel and top slag samples were taken according to the route shown in Figure 1. The steel used for this work has a chemical composition which can be expressed as DIN 38MnS6 standard. All samples correspond to the same steelmaking plant. This study was performed by taking a total of 16 (sixteen) samples divided evenly before and after vacuum degassing treatment, considering (8) steel samples and (8) slag samples. Steel samples were collected using Samp-O-Line (from Heraeus Electro-Nite) without deoxidizer and analyzed by ASPEX equipment ${ }^{13,18-21}$ model Explorer, equipped with SEM/EDS system. The analyzed area for all steel samples composes the range of 54.3-83.6 $\mathrm{mm}^{2}$. Steel chemical composition analyses were carried out using an ARL 3560 Optical Emission Spectrometer to determine calcium $(\mathrm{Ca})$ and aluminum (Al) contents and LECO CS-444LS to determine sulfur (S $)^{4,21}$ contents. Finally, slag samples were analyzed by X-ray fluorescence (XRF) using Philips equipment, model PW2600. The inclusions analysis was classified in three different diameter ranges, namely 2.5-5, 5-15 and $\geq 15 \mu \mathrm{m}$, for each steel sample.

The ladle used for this study has a volume of $8.9 \mathrm{~m}^{3}$ of steel, yielding $62 \mathrm{t}$ of liquid steel with a density of $6940 \mathrm{~kg} /$ $\mathrm{m}^{322}$. The stirring process is performed by a single porous plug localized in the center of the ladle bottom. The average flow rate during vacuum is about $125 \mathrm{Nl} / \mathrm{min}$. For all samples, the vacuum time at low pressure $(<1.5 \mathrm{mbar})$ and the lowest pressure reached were approximately $10 \mathrm{~min}$ and $0.8 \mathrm{mbar}$, respectively. After vacuum degassing the steel is adjusted according to its chemical composition, then alloy wires are injected into the melt as $\mathrm{Al}, \mathrm{Ti}, \mathrm{CaSi}$ (inclusions treatment) and $\mathrm{S}$ (to guarantee steel grade). After wire injection, the ladle is transferred to a continuous casting station. Another

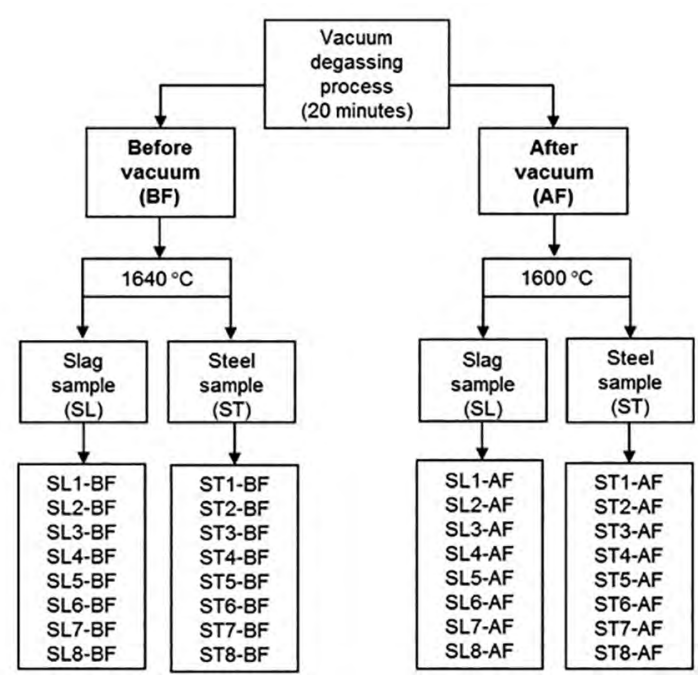

Figure 1. Sample process in the steelmaking route.

important data to consider is the temperature observed during the vacuum degassing stage. The temperature of the steel upon arrival of the degasser is $1640^{\circ} \mathrm{C}$, whereas after vacuum this value decreases to approximately $1600{ }^{\circ} \mathrm{C}$, regarding all samples (Figure 1).

To calculate the slags' effective viscosities, FactSage - a commercial thermodynamic software -, was used. According to Doostmohammadi et al. ${ }^{23}$ the use of computational thermodynamics allows the study of different parameters on the ladle refining efficiency. The thermodynamics simulations were performed using two database set ${ }^{24}$, namely FactPS (for stoichiometrics of pure substances) and FToxid (for oxides and sulfur), in the Equilib software module. The FactSage version applied in this study was 6.4. The calculation of effective viscosity was performed based on two steps: (a) calculation of the liquid viscosity through FactSage using the Viscosity module and after that (b) application of the Roscoe-Einstein method ${ }^{25}$ for determination of the effective viscosity (considering the solid particles), as follows in Equation 1. The liquid viscosity calculation in FactSage can be found in detail in an earlier study ${ }^{26}$.

$$
\eta=\eta_{0}(1-\rho f)^{-2.5}
$$

Where $\eta_{0}$ is the liquid viscosity and $\eta$ the effective viscosity, both in Pa.s. The solid fraction parcel is expressed as $f$. The factor $\rho$ represents a parameter of solid interaction that in this study was equal to the unity, considering a dilute concentration of spherical particles with different $\operatorname{sizes}^{25}$.

To increase the metal-slag rate, injected gas is commonly used, which also promotes a thermal and chemical homogenization ${ }^{27}$. At industrial installations, accurate measurements of the blowing gas (usually Ar) are not possible, due to the possibility of leakages in the pipes ${ }^{6,7}$. However, an indirect method ${ }^{6,28,29} \mathrm{can}$ be applied to calculate a kinetic 
parameter that is associated to the stirring energy, as shown in Equation 2. This parameter, defined as $\beta$, allows for the definition of a relationship between the stirring process and its steel cleanliness potential.

$$
\beta_{s}=k_{s} *\left(\frac{A}{V}\right) * t
$$

As seen, the stirring energy $(\beta$ s $)$ was obtained by a multiplier factor, known as sulfur mass transfer coefficient $(k)$, with three other variables: volume of liquid steel $(V)$, steel-slag interface area $(A)$ and time elapsed $(t)$. This parameter $\left(\beta_{\mathrm{s}}\right)$ returns a numeric value that indicates the intensity of the stirring process. In other words, this parameter is able to indirectly measure the steel and slag interaction from the reduction of the sulfur content in the liquid steel. The units of $k, V, A$ and $t$ were used in $\mathrm{m} . \mathrm{min}^{-1}, \mathrm{~m}^{3}, \mathrm{~m}^{2}$ and min, respectively. The ladle section of the slag line was considered as elliptic shape, so the steel-slag interface is estimated to be $3.73 \mathrm{~m}^{2}$. The time elapsed ( $t$ ) was the same for all samples (20 minutes). The thickness of slag, although it may produce effects in the interaction process between steel and $\operatorname{slag}^{30}$, was not considered for study purposes, since during the secondary refining the mass of added slag formers (lime, dolomite, alumina and $\mathrm{MgO}$ ) in the ladle was practically constant in all the studied heats, being in the range of 2.3 to $2.6 \mathrm{t}$.

In order to calculate the mass transfer coefficient, $k_{\mathrm{s}}$, the Mendez et al. ${ }^{31}$ method was adopted, as follows in Equation 3 and the $k_{\mathrm{s}}$ value was obtained by applying the MS Excel Solver tool.

$$
\frac{[S]}{\left[S_{0}\right]}=\frac{1}{1+R L_{s}}\left[1+R L_{s} \exp ^{\left(\frac{-k_{s}\left(1+R L_{s}\right)}{R L_{s}} t\right)}\right]
$$

Where $[S]$ and $\left[S_{0}\right]$ are, final and initial sulfur within the steel for the elapsed time, respectively. The $R$ factor corresponds to the ratio between slag and steel weight. Finally, $L_{\mathrm{s}}$ is the sulfur partition ratio, calculated as shown in Equation $4^{32}$.

$$
L_{s}=(S) /[S]
$$

Where $(S)$ is the sulfur content in the slag composition. The compositions are given in mass percentages. All data was provided from routine measurements.

\section{Results and Discussion}

\subsection{Slag and steel composition}

The resulting chemical compositions of the slag and steel samples taken before and after vacuum degassing are shown in Tables I and II, respectively, including averages and standard deviation (std.) for each constituent.
Table I shows that the chemical composition of slags is quite similar before and after vacuum degassing. On the other hand, steel composition presents some changes, as evidenced in Table II. Calcium and sulfur decrease for all heats, after vacuum treatment. Steneholm, Andersson, Tilliander and Jönsson ${ }^{4}$ report that 20 minutes of desulphurization leads to a removal of about $50 \%$ of sulfur from its initial concentration. Particularly, in this work, the average reduction in sulfur after vacuum degassing reaches approximately $38.5 \%$, at the same time of degassing treatment (20 min). As commented previously, the addition of aluminum in the liquid steel for composition adjustment occurs after vacuum degassing treatment, so the total aluminum content is low during the vacuum stage ( $\max 0.007$ wt.\%), according Table II, provided during deoxidation ${ }^{33,34}$ in tapping stage, before ladle furnace (LF) process. It is possible to estimate the aluminum present in the form of oxides $\left(\mathrm{Al}_{\text {oxide }}\right)$ through the difference between the contents of $\mathrm{Al}_{\text {total }}$ and $\mathrm{Al}_{\text {soluble }}$. Although $\mathrm{Al}_{\text {total }}$ did not show any variation during the vacuum process, the $\mathrm{Al}_{\text {oxide }}$ content showed a decrease (average of $10 \mathrm{ppm}$ ) in almost all the samples collected, as shown in Table II, indicating a possible flotation of alumina-rich inclusions during vacuum degassing.

\subsection{Inclusion population analysis}

All steel samples were analyzed with regards to their inclusion population. Figures $2 \mathrm{a}$ and $2 \mathrm{~b}$ depict the average frequency of inclusion with standard deviations, considering only oxides, for three ranges of average inclusion diameter. Sulfide type inclusions ( $\mathrm{MnS}$ and oxy-sulfide) were also found in the samples, but in minor amount compared to oxides. Oxides represented more than $96 \%$ and $81 \%$ of the total inclusions detected, before and after vacuum degassing, respectively. Thus, these sulfide species were not considered to facilitate the inclusionary analysis. Furthermore, $\mathrm{MnS}$ inclusions may be formed probably as a consequence of the solidification process of the samples ${ }^{21}$ and do not represent the reality of the liquid steel, at the vacuum degasser. Regarding liquid steel, the presence of oxy-sulfide type inclusions increases after vacuum. These inclusions were rich especially in calcium, which can be attributed to the interaction with the sulfur during the stirring process of the liquid steel under vacuum and they were not removed by the slag. However, as commented, the focuses of the inclusion analysis were made only with respect to the great population of oxides.

It is possible to observe a decrease in inclusion population after the vacuum degassing process (Figure 2). This fact confirms the effects from the vacuum station on the inclusion removal. The inclusion removal average during vacuum degassing reaches 64,75 and $78 \%$ for the diameter ranges of $2.5-5,5-15 \mathrm{e} \geq 15 \mu \mathrm{m}$, respectively. The greater average is associated to with the $\geq 15 \mu \mathrm{m}$ inclusion size and was to be expected, in view of the flotation phenomena. Bigger 
Table 1. Slag composition (wt.\%) before (BF) and after (AF) vacuum treatment.

\begin{tabular}{cccccccccccc}
\hline & \multicolumn{2}{c}{$\mathrm{CaO}$} & \multicolumn{2}{c}{$\mathrm{Al}_{2} \mathrm{O}_{3}$} & \multicolumn{2}{c}{$\mathrm{MgO}$} & \multicolumn{3}{c}{$\mathrm{SiO}_{2}$} & \multicolumn{3}{c}{$\mathrm{S}$} \\
\hline Sample & $\mathrm{BF}$ & $\mathrm{AF}$ & $\mathrm{BF}$ & $\mathrm{AF}$ & $\mathrm{BF}$ & $\mathrm{AF}$ & $\mathrm{BF}$ & $\mathrm{AF}$ & $\mathrm{BF}$ & $\mathrm{AF}$ \\
\hline SL1 & 51.26 & 51.63 & 7.24 & 7.96 & 11.81 & 12.81 & 29.07 & 26.84 & 0.61 & 0.77 \\
SL2 & 47.40 & 47.11 & 8.35 & 8.10 & 14.42 & 14.46 & 29.33 & 29.79 & 0.50 & 0.55 \\
SL3 & 49.02 & 52.09 & 5.80 & 7.07 & 10.23 & 12.21 & 34.61 & 27.99 & 0.34 & 0.64 \\
SL4 & 55.41 & 54.83 & 9.79 & 9.32 & 9.60 & 9.56 & 24.23 & 25.10 & 0.97 & 1.19 \\
SL5 & 55.71 & 51.55 & 8.12 & 9.03 & 9.35 & 8.05 & 25.55 & 30.12 & 1.27 & 1.25 \\
SL6 & 50.61 & 51.39 & 8.87 & 9.35 & 10.57 & 12.05 & 29.57 & 26.39 & 0.38 & 0.82 \\
SL7 & 45.40 & 46.11 & 8.74 & 8.31 & 16.47 & 15.48 & 28.96 & 29.51 & 0.43 & 0.59 \\
SL8 & 47.21 & 50.31 & 9.92 & 9.78 & 11.03 & 11.36 & 30.99 & 27.63 & 0.85 & 0.91 \\
Average & 50.60 & 51.06 & 8.41 & 8.69 & 11.76 & 12.09 & 29.23 & 28.14 & 0.67 & 0.84 \\
Std. & 3.78 & 2.81 & 1.35 & 0.91 & 2.51 & 2.42 & 3.17 & 1.79 & 0.33 & 0.26 \\
\hline
\end{tabular}

Table 2. Steel composition before (BF) and after (AF) vacuum treatment.

\begin{tabular}{|c|c|c|c|c|c|c|c|c|c|c|c|c|c|c|c|c|}
\hline \multirow[b]{2}{*}{ Sample } & \multicolumn{2}{|c|}{$\mathrm{C}^{+}$} & \multicolumn{2}{|c|}{$\mathrm{Mn}^{+}$} & \multicolumn{2}{|c|}{$\mathrm{Si}^{+}$} & \multicolumn{2}{|c|}{$\mathrm{Ca}^{*}$} & \multicolumn{2}{|c|}{$\mathrm{S}^{*}$} & \multicolumn{2}{|c|}{$\mathrm{Al}_{\text {total }} *$} & \multicolumn{2}{|c|}{$\mathrm{Al}_{\text {soluble }}{ }^{*}$} & \multicolumn{2}{|c|}{$\mathrm{Al}_{\text {oxide }}{ }^{*}$} \\
\hline & $\mathrm{BF}$ & $\mathrm{AF}$ & $\mathrm{BF}$ & $\mathrm{AF}$ & $\mathrm{BF}$ & $\mathrm{AF}$ & $\mathrm{BF}$ & $\mathrm{AF}$ & $\mathrm{BF}$ & $\mathrm{AF}$ & $\mathrm{BF}$ & $\mathrm{AF}$ & $\mathrm{BF}$ & $\mathrm{AF}$ & $\mathrm{BF}$ & $\mathrm{AF}$ \\
\hline ST1 & 0.371 & 0.378 & 1.299 & 1.363 & 0.653 & 0.672 & 36 & 10 & 120 & 80 & 70 & 60 & 40 & 40 & 30 & 20 \\
\hline ST2 & 0.365 & 0.363 & 1.388 & 1.386 & 0.660 & 0.655 & 14 & 6 & 80 & 60 & 60 & 50 & 40 & 30 & 20 & 20 \\
\hline ST3 & 0.357 & 0.267 & 1.339 & 1.322 & 0.653 & 0.642 & 8 & 5 & 120 & 90 & 50 & 50 & 40 & 40 & 10 & 10 \\
\hline ST4 & 0.360 & 0.356 & 1.313 & 1.307 & 0.649 & 0.631 & 7 & 3 & 160 & 90 & 60 & 60 & 40 & 50 & 20 & 10 \\
\hline ST5 & 0.362 & 0.369 & 1.306 & 1.335 & 0.656 & 0.657 & 6 & 4 & 150 & 80 & 60 & 60 & 40 & 60 & 20 & 0 \\
\hline ST6 & 0.366 & 0.373 & 1.355 & 1.339 & 0.645 & 0.636 & 8 & 5 & 130 & 70 & 50 & 50 & 30 & 40 & 20 & 10 \\
\hline ST7 & 0.347 & 0.356 & 1.314 & 1.355 & 0.617 & 0.636 & 9 & 7 & 120 & 70 & 60 & 50 & 30 & 40 & 30 & 10 \\
\hline ST8 & 0.354 & 0.365 & 1.320 & 1.328 & 0.635 & 0.693 & 9 & 4 & 130 & 80 & 60 & 60 & 30 & 40 & 30 & 20 \\
\hline Average & 0.360 & 0.353 & 1.329 & 1.342 & 0.646 & 0.653 & 12.1 & 5.5 & 126.3 & 77.5 & 58.8 & 55 & 36.3 & 42.5 & 22.5 & 12.5 \\
\hline Std. & 0.008 & 0.036 & 0.030 & 0.025 & 0.014 & 0.021 & 9.9 & 2.2 & 23.9 & 10.4 & 6.4 & 5.3 & 5.2 & 8.9 & 7.1 & 7.1 \\
\hline
\end{tabular}
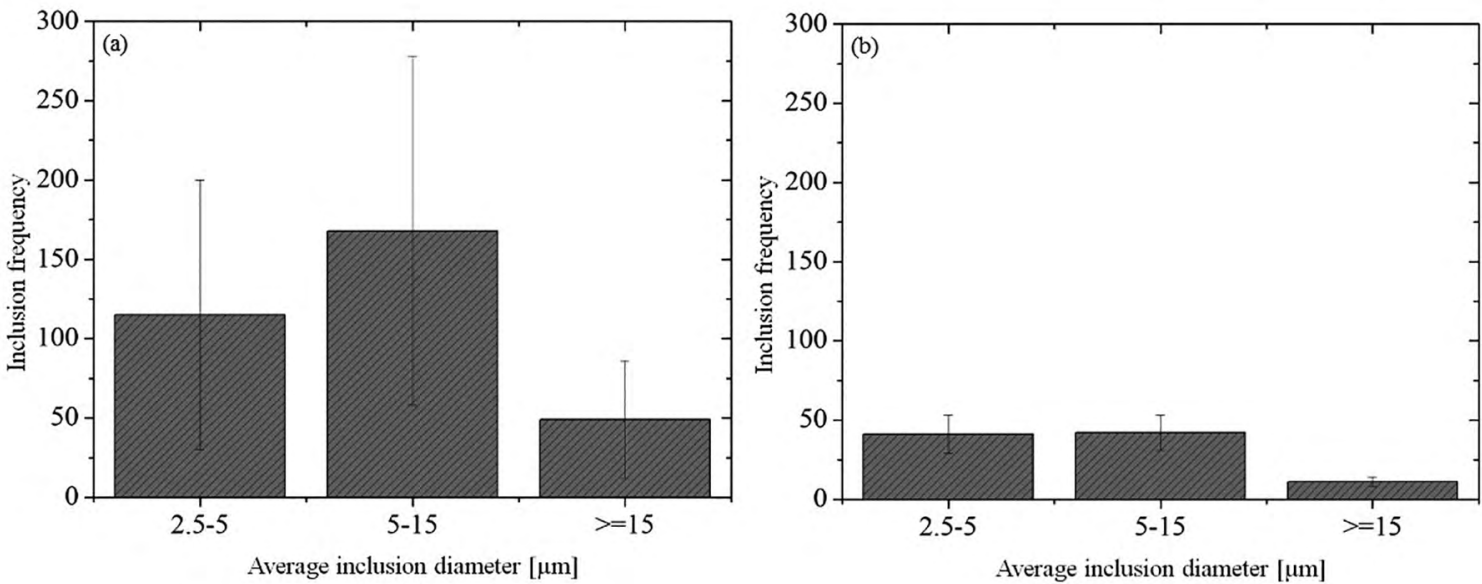

Figure 2. Inclusion frequency for each average inclusion diameter range (a) before and (b) after vacuum degassing.

inclusions have higher rising velocity and are more easily removed from the liquid steel ${ }^{14}$. Still, a higher deviation in the case before vacuum treatment (Figure 2a) was noticed, for the three inclusion diameter ranges. The population of inclusions for the different steel samples before the vacuum stage show high standard deviations due to variations in the frequency of inclusions observed. On the other hand, Figure $2 \mathrm{~b}$ shows a more stabilized condition, guaranteed by the 
vacuum process, which in turn, decreased the frequency of inclusions to less than 50 inclusions, in relation to the three diameter ranges considered.

This behavior of inclusion population decreasing after degassing treatment is also reported by others authors ${ }^{6,8-11}$. However, it is also reported in some studies ${ }^{6,8}$ that inclusions may increase to larger than $11.3 \mu \mathrm{m}$ after vacuum treatment, which may be associated to the entrapment of particles of the ladle's refractory lining during the degassing activity. Also, Capurro, Cerrutti and $\mathrm{Cicutti}^{6}$, affirm that average inclusion size may increase after vacuum degassing, through a coalescence mechanism. However, in this work, the opposite result was noted. Figure 3 illustrates the behavior of the size variations of inclusions following the vacuum treatment performed in this study.

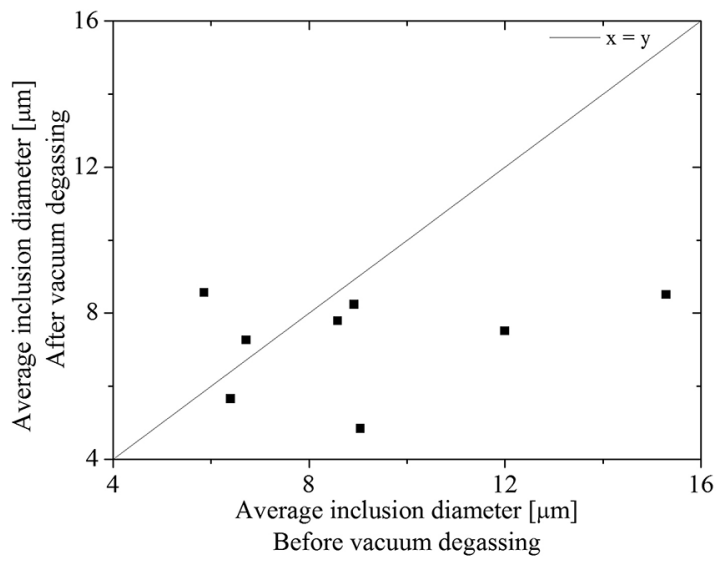

Figure 3. Inclusion average size change during vacuum degassing.

Payandeh and Soltanieh ${ }^{34}$ reported that collision of two particles (inclusions) does not always promote their joining. The authors propose that at extremely high agitation what may occur is the inverse effect, collapsing big inclusions, previously formed, into smaller ones. In the study carried out by $\mathrm{Kang}^{8}$, the author found that the agglomeration between inclusions is dependent of its species. The results obtained by the author ${ }^{8}$ indicated that alumina inclusions present a rapid growth through the process of attraction and agglomeration, unlike the particles composed of calcium aluminates and spinels, which presented low levels of agglomeration. Also, $\mathrm{Kang}^{8}$ conducted a study of inclusion population change regarding the ladle age and observed that all evaluated heats show an increase in the number of inclusions larger than $11.3 \mu \mathrm{m}$ using aged ladles. In contrast, the author also noted that when using a new ladle, the number of large inclusions decreases after vacuum degassing. Whereas, in this work, the ladle age was not considered, this factor can be an important factor in the understanding of inclusion population evolution before and after vacuum degassing.

The density of inclusions is an important measurement of their degree of steel cleanliness. The change in the density of inclusions along the vacuum degassing process is shown in Figure 4, separated for each heat sample and inclusion diameter range. The results for the density change of the inclusions were achieved by taking the difference between the inclusion density after and before vacuum degassing.

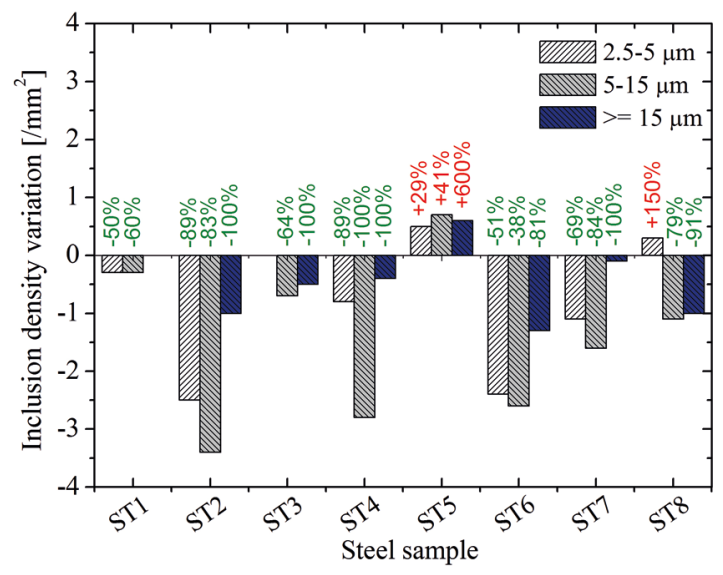

Figure 4. Inclusion density variation after vacuum degassing for each steel sample.

A decrease in density of inclusions for almost all (7) heats sampled after vacuum treatment is noted. However, as illustrated in heat sample ST5, there is an increase in inclusion density after vacuum, for all diameter ranges. An increase of $600 \%$ in the inclusions amount after vacuum is noted when the density goes from 0.1 to 0.6 inclusions/ $\mathrm{mm}^{2}$, considering inclusions $\geq 15 \mu \mathrm{m}$. Steneholm, Anderson and Jönsson ${ }^{10}$ conducted a study in the changes of inclusion characteristics during degassing and also reported an increase in inclusion density after vacuum for some evaluated heats. According to the authors, this should be related to a change in top slag composition. An increase of $\mathrm{CaO}$ content in slag could affect the interfacial properties of inclusion, promoting a difficulty in separation of inclusion for the slag. In fact, slag sample SL5 (related to ST5) presented higher $\mathrm{CaO}$ related to others samples, but erosion of the ladle glaze may not be disregard ${ }^{35}$. Likewise, Capurro, Cerrutti and Cicutti ${ }^{6}$ observed an increase in density for inclusions bigger than $11.3 \mu \mathrm{m}$. In sample ST8 an increase in density by smaller inclusions, in the $2.5-5 \mu \mathrm{m}$ range is noticed.

\subsection{Inclusion chemical composition}

After vacuum treatment it was possible to observe that the inclusions' chemical compositions differed from before the vacuum treatment. A comparison of the evolution of the compositions between inclusions and slag, in relation to the conditions before and after the vacuum treatment, is shown in Figure 5. As the points approach the line " $y=x$ ", the equality between the chemical compositions is given. It must be taken into consideration that the oxides presented are pure in slag and inclusions and therefore represent a limiting factor. 


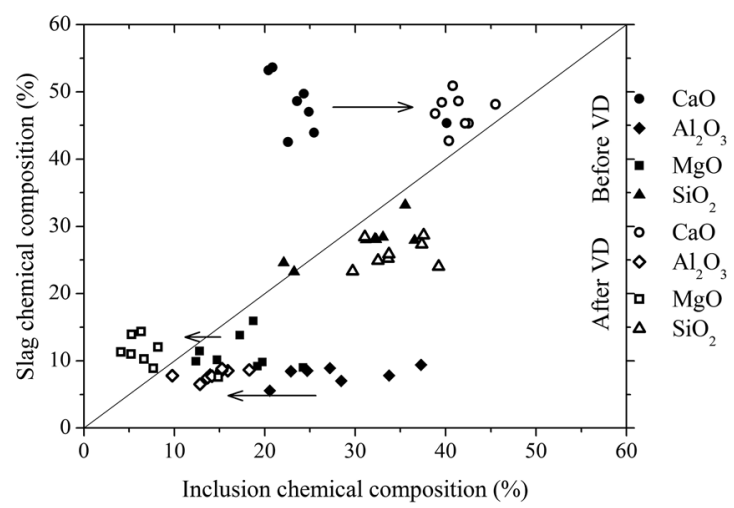

Figure 5. Inclusion and slag chemical compositions evolution before and after vacuum degassing in $\mathrm{CaO}, \mathrm{Al}_{2} \mathrm{O}_{3}, \mathrm{MgO}$ and $\mathrm{SiO}_{2}$ content.

Analyzing Figure 5, an increase in $\mathrm{CaO}$ content is noted and this fact could be explained by interaction between slag and steel, during stirring under vacuum ${ }^{6}$. According to Médioni ${ }^{12}$, a strong stirring and increased kinetic during vacuum degassing is beneficial for approaching equilibrium between slag and inclusions. The same author reported that the values of slag and inclusion composition are not similar, and this could be explained by other inclusion sources apart from slag entrapment. As proposed previously ${ }^{35}$ and according to Médioni ${ }^{12}$, these sources of inclusions can be described by ladle lining erosion. With the approximation between the inclusion and slag compositions identified by Figure 5, deeper analysis reveals a decrease in the dissolution driving force of inclusion by the slag ${ }^{14}$. The difference observed between the inclusion and slag compositions in the samples before the vacuum treatment indicate the condition with higher driving force for the dissolution of these particles.

The $\mathrm{CaO}$ content in inclusions increases after vacuum degassing. However, $\mathrm{Al}_{2} \mathrm{O}_{3}$ and $\mathrm{MgO}$ content are diminished. Inclusion composition seems to approach similarity with the slag, as illustrated in Figure 5. On the other hand, $\mathrm{SiO}_{2}$ content did not show a great variation in inclusion composition, but the composition of the inclusions in this constituent was already very close to the composition of the slag even before the degassing process. This fact is illustrated through the points in Figure 5, after vacuum degassing treatment, approaching the line " $y=x "$. This behavior has been reported elsewhere ${ }^{6,10}$.

As commented before, the steel composition in $\mathrm{Ca}$ before and after vacuum degassing (Table II) decreases. Probably, this can be related to the calcium incorporation into non-metallic inclusions by association with dissolved oxygen $^{36}$, providing an increase in $\mathrm{CaO}$ content in inclusion composition.

Considering the effect of the degassing process in the size and composition of inclusions, the condition (a) before and (b) after vacuum treatment was plotted, as shown in Figure 6.
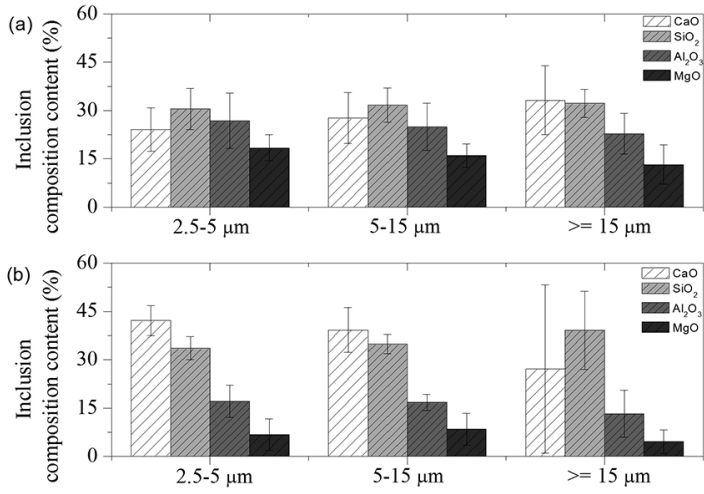

Figure 6. Chemical composition and diameter range of inclusions (a) before and (b) after vacuum treatment.

It can be seen from Figures $6 \mathrm{a}$ and $6 \mathrm{~b}$ that there are no major differences between the different sized inclusions with respect to chemical composition. In fact, for the before vacuum condition (Figure 6a), the compositions are very similar for the three diameter bands. For the steel samples collected after the vacuum (Figure 6b), the compositions are also similar across the three ranges, although there is a greater deviation in the $\mathrm{CaO}$ content for inclusions greater than or equal to $15 \mu \mathrm{m}$. The evolution of the oxides in Figure 6 is in agreement with the results of Figure 5.

The average composition of inclusions, separated by ranges, is shown in Figure $7 \mathrm{a}$ and $7 \mathrm{~b}$, which illustrates the inclusion positions in a $\mathrm{CaO}-\mathrm{SiO}_{2}-\mathrm{Al}_{2} \mathrm{O}_{3}-\mathrm{MgO}$ pseudo-ternary system ( $\mathrm{MgO}$ fixed) before and after vacuum degassing with isothermal cuts, based on the start and end temperatures of the degassing process of 1640 and $1600{ }^{\circ} \mathrm{C}$, respectively.

This type of ternary diagram was chosen based in the high $\mathrm{SiO}_{2}$ content present during vacuum treatment.

From Figure 7, the effect of temperature on the displacement of non-metallic inclusions, as well as the different phases present, is verified. It is noted that the decrease in temperature with the decrease of the $\mathrm{MgO}$ content in the inclusions (Figure $7 \mathrm{~b})$ promotes the appearance of the phases corresponding to regions 4, 9 and 10 in the diagram, when compared to the condition before the vacuum treatment.

In Figure 7a, inclusion compositions are presented with differences, considering all diameter ranges. These inclusions are localized in the center of the pseudo-ternary diagram, associated with a liquid phase (ASlag-liq) and some particles inside the spinel zone with a liquid portion (ASpinel + ASlag-liq). Alexis et al. ${ }^{37}$ also reported spinel based inclusions before vacuum treatment. After vacuum degassing, the greater part of inclusions is in the liquid zone (ASlag-liq) and towards the regions 10 and 9, where there exist $\mathrm{C}_{2} \mathrm{~S}\left(\mathrm{a}-\mathrm{Ca}_{2} \mathrm{SiO}_{4}\right.$ ), oxides (AMonoxide) and liquid (ASlag-liq) phases. This displacement shows a decrease in $\mathrm{Al}_{2} \mathrm{O}_{3}$ particle content in the pseudo-ternary diagram. Also 

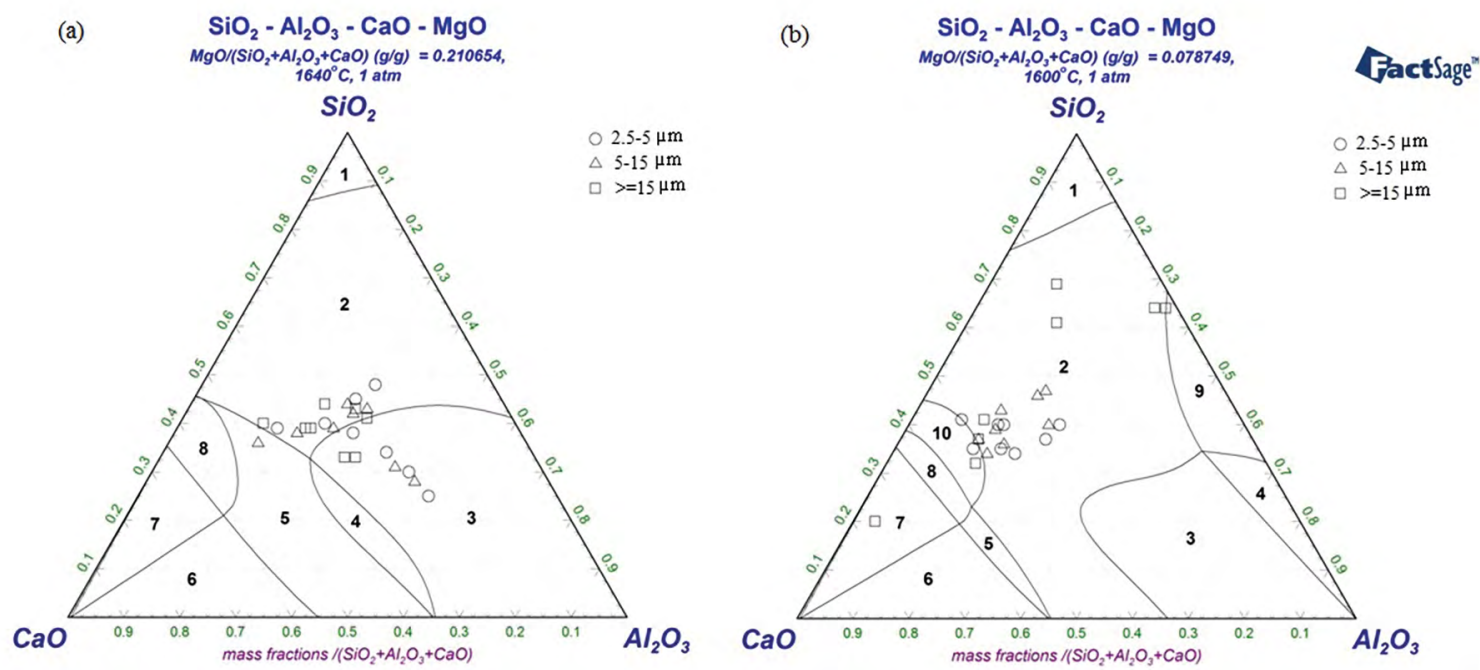

Figure 7. Inclusion distribution for each diameter range $(\mu \mathrm{m})$ (a) before and (b) after vacuum treatment. Phases: 1 - ASlag-liq + ASlag-liq $\# 2$; 2 - ASlag-liq; 3 - ASlag-liq + ASpinel; 4 - ASlag-liq + ASpinel + (a) AMonoxide, (b) Mullite; 5 - ASlag-liq + AMonoxide; 6 - ASlag-liq + AMonoxide + AMonoxide\#2; 7 - ASlag-liq + AMonoxide + AMonoxide\#2 + a-Ca $\mathrm{SiO}_{4} ; 8$ - ASlag-liq $+\mathrm{AMonoxide}+\mathrm{a}_{-} \mathrm{Ca}_{2} \mathrm{SiO}_{4} ; 9-$ ASlag-liq + Mullite; 10 - ASlag-liq + $\mathrm{a}_{-} \mathrm{Ca}_{2} \mathrm{SiO}_{4}$

it is possible to observe a greater dispersion for inclusions with diameter $\geq 15 \mu \mathrm{m}$, indicating the possibility of these inclusions being originated from exogenous sources, such as refractory lining.

It is interesting to present also the morphological aspects of the inclusions as a function of the vacuum process. Morphology characterization of inclusions from before and after vacuum degassing is shown in Figures 8a to 8d.

The typical inclusion morphologies found before and after degassing treatment are principally constituted of $\mathrm{CaO}-$ $\mathrm{SiO}_{2}-\mathrm{Al}_{2} \mathrm{O}_{3}-\mathrm{MgO}$ (with low and high $\mathrm{Al}_{2} \mathrm{O}_{3}$ ), $\mathrm{MgO}-\mathrm{Al}_{2} \mathrm{O}_{3}$ (spinel) and $\mathrm{CaO}-\mathrm{SiO}_{2}$, as illustrated by Figure 8 . The $\mathrm{CaO}-\mathrm{SiO}_{2}-\mathrm{Al}_{2} \mathrm{O}_{3}-\mathrm{MgO}$ (high $\mathrm{Al}_{2} \mathrm{O}_{3}$ ) and spinel type inclusions were characteristic of samples collected before vacuum, as shown in Figure $8 \mathrm{a}$ and $8 \mathrm{~b}$, respectively. After vacuum, the inclusions of $\mathrm{CaO}-\mathrm{SiO}_{2}-\mathrm{Al}_{2} \mathrm{O}_{3}-\mathrm{MgO}\left(\right.$ low $\mathrm{Al}_{2} \mathrm{O}_{3}$ ) and $\mathrm{CaO}-\mathrm{SiO}_{2}$ were more pronounced in the steel samples, respectively illustrated by Figures $8 \mathrm{c}$ and $8 \mathrm{~d}$. These types of inclusions have also been reported in other works during sampling under vacuum treatment ${ }^{1,8,12}$.

\subsection{Effective viscosity of slags}

One of the most important physical properties is slag viscosity that has strong impact on ladle refining ${ }^{38}$. According to Jiang, Wang and Wang ${ }^{39}$, a change in slag composition would result in a change of viscosity, which affects the absorption ability of inclusions. An attempt to identify the influence of the effective viscosity of the slag on the inclusion density variation during the vacuum degassing is shown in Figure 9, considering a temperature of $1600^{\circ} \mathrm{C}$ (at the end of the vacuum treatment) for the three diameter ranges of inclusion.
It is noted that lower viscosity values (close to $0.20 \mathrm{~Pa} . \mathrm{s}$ ) are more effective in steel cleanliness. However, viscosity values greater than $0.40 \mathrm{~Pa}$.s, can be harmful to the inclusion removal by slag and an increased trend in the inclusion density after vacuum, for all ranges of inclusions, is observed. The higher correlation $\left(\mathrm{R}^{2}=0.50\right)$ identified by the diameter range with the largest population of inclusions $(5-15 \mu \mathrm{m})$ shows that despite the other factors affecting the removal of inclusions, the effective viscosity of the slag is still a good indicator associated with steel cleanliness. In fact, regarding the steel cleanliness, a lower effective viscosity promotes an increase in slag capacity to remove inclusion from steel bath, since the interaction between slag and steel is optimized. Choi, Lee and $\mathrm{Kim}^{40}$ demonstrated that, the lower the viscosity is, an increased mass transfer coefficient is noted, intensifying the dissolution rate of inclusions by slag. Additionally, the dissolution rate can also be increased through an enhanced driving force, achieved when slag and inclusion composition present a greater difference ${ }^{7}$. The higher inclusion density change (approximately -6.6 inclusions $/ \mathrm{mm}^{2}$ ) is observed in the $5-15 \mu \mathrm{m}$ range, as illustrated in Figure 9. Capurro, Cerrutti and Cicutti ${ }^{6}$ obtained values of effective viscosity lower than 0.07 Pa.s and changes in oxide inclusion density near -2 inclusions $/ \mathrm{mm}^{2}$. Thus, the same behavior of effective viscosity in steel cleanliness was reported.

\subsection{Kinetic stirring parameter}

One of the objectives of this study was to verify, during the degassing process, the effect of the kinetic parameter of agitation $\left(\beta_{\mathrm{s}}\right)$ on the inclusion cleanliness of special steel DIN $38 \mathrm{MnS6}$. For this, it was necessary to obtain and relate the values of the kinetic parameter to the variation of the density 


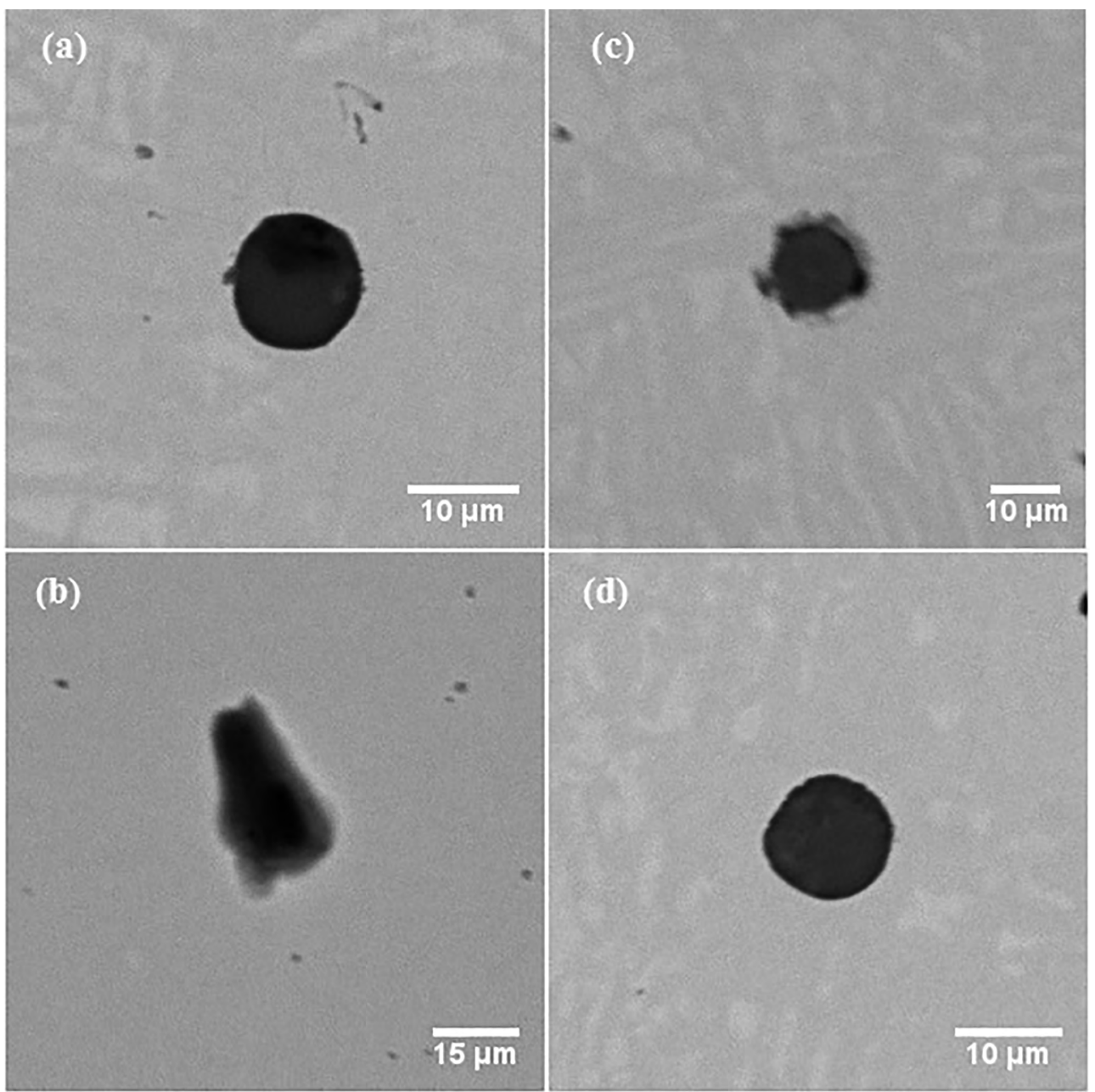

Figure 8. Morphology characterization of inclusions from $(\mathrm{a}, \mathrm{b})$ before and $(\mathrm{c}, \mathrm{d})$ after vacuum degassing.

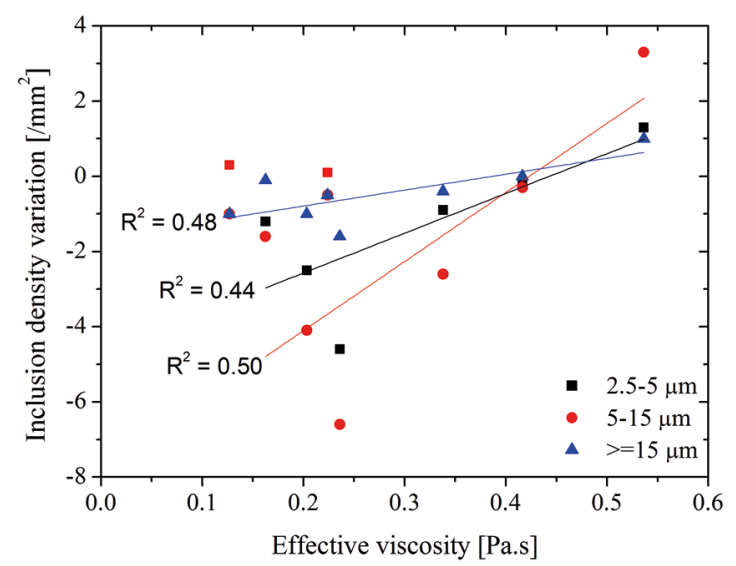

Figure 9. Inclusion density variation related to the effective viscosity of all slag samples at $1600{ }^{\circ} \mathrm{C}$.

and the chemical composition of the non-metallic inclusions. Results related to the desulphurization of the steel during vacuum treatment are also presented, in order to indirectly measure the slag and steel interaction.
Figure 10 shows the variation of the inclusion densities after the vacuum degassing as a function of the kinetic stirring parameter, $\beta_{\mathrm{s}}$. Four ranges of $\beta_{\mathrm{s}}$ were considered: $<0.25,0.25$ $0.30,0.30-0.35$ and $>0.35$. In the study proposed by Capurro, Cerrutti and Cicutti ${ }^{6}$ smaller values than the unit for $\beta_{\mathrm{s}}$ were found, however, higher values were observed, suggesting more intense agitation in the process evaluated by the authors.

From the value of 0.25 for the kinetic parameter, a certain tendency can be observed for inclusions in the range of 2.5-15 $\mu \mathrm{m}$ with respect to the increase of $\beta_{\mathrm{s}}$. As described by Reis, Bielefeldt and Vilela ${ }^{26}$, particles of smaller diameter have a lower rate of ascent and, therefore, are more difficult to remove by slag through the flotation phenomenon. Thus, the gas injection becomes an important tool to push smaller diameter inclusions directly to the slag/steel interface and, from there, the phenomena of separation and dissolution occur.

For inclusions greater than or equal to $11.3 \mu \mathrm{m}$, Capurro, Cerrutti and Cicutti ${ }^{6}$ and Capurro et al. ${ }^{7}$ obtained results different from those previously mentioned. According to the authors, an increase of $\beta_{\mathrm{s}}$, which is associated with an increase of stirring, can promote slag emulsification 


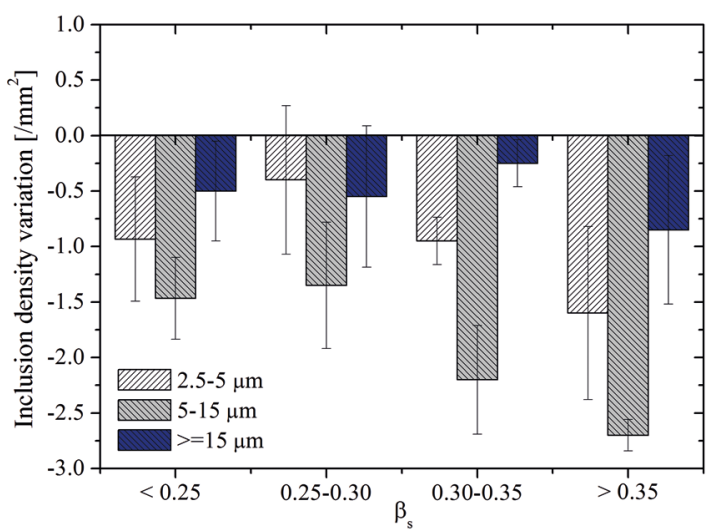

Figure 10. Change in inclusion density as a function of $\beta_{\mathrm{s}}$ (kinetic parameter).

phenomenon and new inclusions could be generated. It is possible to obtain new inclusions or "return" inclusions in the liquid steel, such as reoxidation, cleaning of the slag/ steel interface with particles trapping inside the steel and erosion of the refractory ladle wall ${ }^{41}$. For inclusions of the diameter range $\geq 15 \mu \mathrm{m}$, a dependence of the inclusionary cleanliness with the parameter $\beta_{\mathrm{s}}$ is not clearly observed, which verifies the smaller values related to the variation of inclusion density, for the greatest diameter range.

The kinetic parameter of stirring can also be related to the desulphurization, i.e. removal of $\mathrm{S}$ from the liquid steel, being a good indicator of the slag/steel interaction. Figure 11 shows the variation of the $\mathrm{S}$ content in the liquid steel as a function of the kinetic parameter, $\beta_{\mathrm{s}}$.

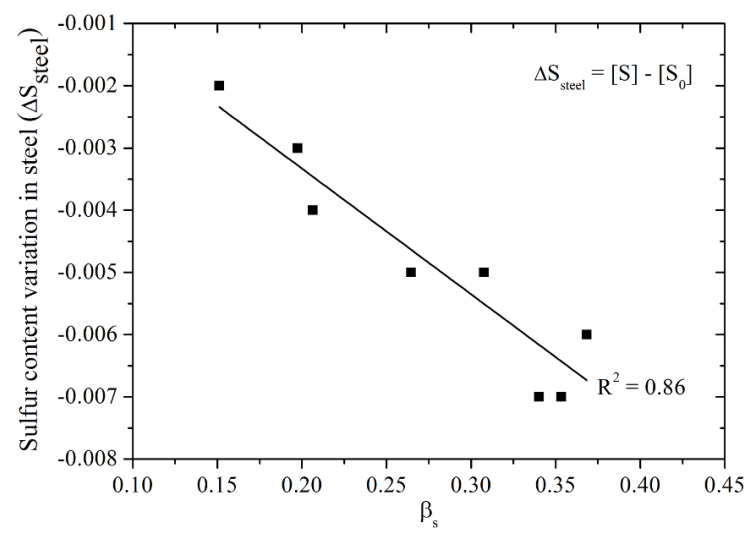

Figure 11. Change of the $\mathrm{S}$ content in the liquid steel as a function of $\beta_{\mathrm{s}}$.

Considering that these are industrial data, Figure 11 shows an excellent correlation $\left(\mathrm{R}^{2}=0.86\right)$ between the desulphurization of the liquid steel and the kinetic parameter. It is observed that with an increase of the kinetic parameter, a variation of the $\mathrm{S}$ content is even more negative, therefore decreasing the $\mathrm{S}$ content in the liquid steel related to the vacuum degassing effect. This means, in other words, that an increase in ladle stirring increases the interaction between steel and slag, promoting a greater absorption of $\mathrm{S}$ by the slag.

Still analyzing the $\beta_{\mathrm{s}}$, Figure 12 illustrates the influence of the stirring parameter in the inclusion content change for (a) $\mathrm{CaO}$, (b) $\mathrm{SiO}_{2}$, (c) $\mathrm{Al}_{2} \mathrm{O}_{3}$ and (d) $\mathrm{MgO}$. The objective is to filter the inclusion composition and show the evolution of each compound with the stirring process, as adopted in previous studies ${ }^{6,7}$. In all figures, the adjustment of a linear fit was performed in order to verify the tendency effect produced in the composition of the inclusions with $\beta_{\mathrm{s}}$.

With respect to the low correlation values shown in Figure 12, it can be said that they are considered acceptable in view of the industrial environment in which this study was developed. The results were confronted with an analysis of the population of inclusions before and after the vacuum degassing of a previous work also developed in an industrial plant ${ }^{6,7}$. And, according to the authors mentioned, it was found that for the $\mathrm{CaO}$ content in the inclusions, an increase with the $\beta_{\mathrm{s}}$ increment was obtained. For $\mathrm{Al}_{2} \mathrm{O}_{3}$, there was a decrease in its content. In this study, this behavior is proven, as shown in Figure 12a and 12c. According to the authors ${ }^{6,7}$, a more vigorous stirring promotes the evolution and modification of the chemical composition of non-metallic inclusions present in the liquid steel. For $\mathrm{SiO}_{2}$ (Figure 12b), there is an increase in its content as $\beta_{\mathrm{s}}$ is also increased. Finally, related to the $\mathrm{MgO}$ content, Capurro et al. ${ }^{7}$ reported that with the increase of the kinetic parameter in an elapsed time, the $\mathrm{MgO}$ in the inclusions should increase. However, Figure $12 \mathrm{~d}$ shows no correlation between the $\mathrm{MgO}$ variation in inclusions and the effect of $\beta_{\mathrm{s}}$ for the selected linear fit. It is possible that there is a dependence on the way $\mathrm{MgO}$ is present in the inclusions. In order to better understand the variation of the content of this constituent as a function of the kinetic parameter, a more in-depth investigation of the condition that makes it possible to illustrate the behavior of $\mathrm{MgO}$ versus $\beta_{\mathrm{s}}$ content should be performed.

\section{Conclusions}

The study of steel cleanliness during the vacuum degassing process has shown potential. Considering the operational conditions of this work it can be concluded that:

1. The removal of inclusions during the vacuum reached 64,75 and $78 \%$ for the inclusion size ranges of 2.5-5, 5-15 and $\geq 15 \mu \mathrm{m}$, respectively.

2. After degassing treatment, the average size of inclusions diminished. Although this result is not in accordance with the literature, it is a desired result, in view of the damaging effects of bigger particles on the properties of the steels.

3. Generally, inclusion density decreases after vacuum degassing treatment for the evaluated heats. 

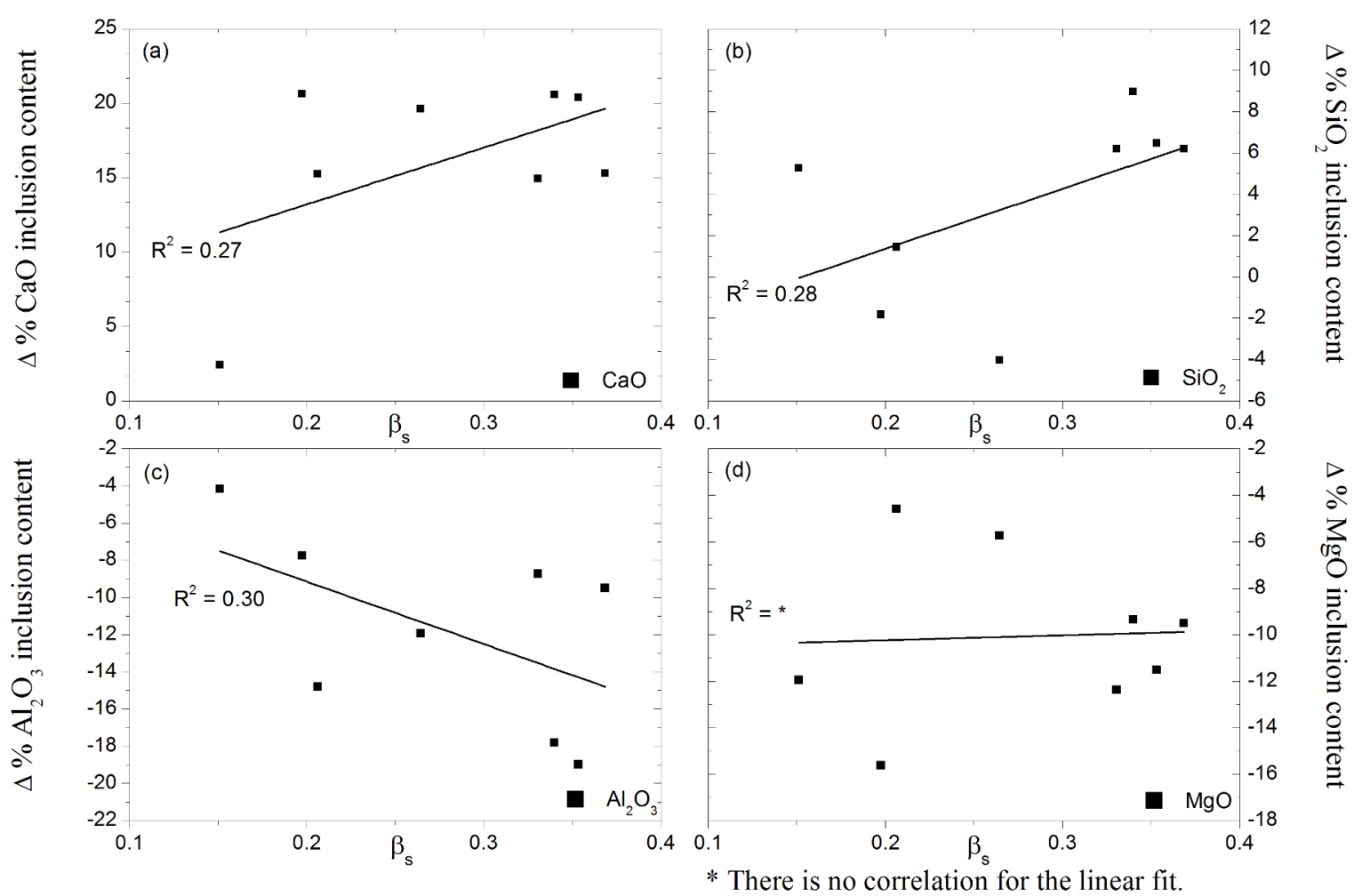

Figure 12. Effect of $\beta_{\mathrm{s}}$ in inclusion content change in (a) $\mathrm{CaO}$, (b) $\mathrm{SiO}_{2}$, (c) $\mathrm{Al}_{2} \mathrm{O}_{3}$ and (d) $\mathrm{MgO}$.

4. The $\mathrm{CaO}$ content in inclusions increased after vacuum degassing. However, $\mathrm{Al}_{2} \mathrm{O}_{3}$ and $\mathrm{MgO}$ content diminished. On the other hand, $\mathrm{SiO}_{2}$ content did not show a great variation in inclusion composition. Inclusions composition seems to approach that of the slag during vacuum treatment.

5. During vacuum degassing, in a pseudo-ternary diagram, inclusions moved from a liquid and spinel phase zone to a liquid zone and towards the regions where $\mathrm{C}_{2} \mathrm{~S}$, oxides and liquid phases exist.

6. The typical inclusion morphologies found before and after degassing treatment are principally constituted of $\mathrm{CaO}-\mathrm{SiO}_{2}-\mathrm{Al}_{2} \mathrm{O}_{3}-\mathrm{MgO}$ (with low and high $\mathrm{Al}_{2} \mathrm{O}_{3}$ ), $\mathrm{MgO}-\mathrm{Al}_{2} \mathrm{O}_{3}$ (spinel) and $\mathrm{CaO}-\mathrm{SiO}_{2}$.

7. Regarding the steel cleanliness, a lower effective viscosity (close to 0.20 Pa.s) promotes an increase in slag capacity to remove inclusions from the steel bath.

8. Slag capacity in inclusion removal is decreased with higher effective viscosity values ( $>0.40$ Pa.s). In this case, an increased trend in inclusion density was observed.

9. The kinetic stirring parameter increase showed a significant effect on the inclusion density variation in the steel, promoting a decrease for the particle in the size range of $2.5-15 \mu \mathrm{m}$. For the range $\geq$ $15 \mu \mathrm{m}$, there was no clear dependence with the parameter $\beta_{\mathrm{s}}$.
10. The increase of $\beta_{\mathrm{s}}$ promotes the decrease of $\mathrm{S}$ content in steel, resulting in the interaction of slag and steel optimization.

11. Finally, related to the effect of $\beta_{\mathrm{s}}$ on the chemical composition of the inclusions, its increase causes reduction of $\mathrm{Al}_{2} \mathrm{O}_{3}$ and increase of $\mathrm{CaO}$ and $\mathrm{SiO}_{2}$ in the inclusions content. Regarding the $\mathrm{MgO}$ content there was no clear correlation.

\section{Acknowledgements}

The authors are grateful for the support provided by National Council of Research (CNPq) and Federal University of Rio Grande do Sul (UFRGS). Special thanks to Eng. Bruna Bartosiaki from Gerdau Charqueadas for implement the sampling process at the melt shop.

\section{References}

1. Riyahimalayeri K, Ölund P. Development of oxide inclusions during vacuum degassing process. Ironmaking \& Steelmaking. 2013;40(4):290-297.

2. Riyahimalayeri K, Ölund P, Selleby M. Effect of vacuum degassing on non-metallic inclusions in an ASEA-SKF ladle furnace. Ironmaking \& Steelmaking. 2013;40(6):470-477.

3. Gottardi R, Partyka A, Miani S, Gemo L. Hydrogen removal efficiency. In: AISTech Proceedings; 2015 May 4-7; Cleveland, OH, USA. p. 2330-2339. 
4. Steneholm K, Andersson M, Tilliander A, Jönsson PG. Removal of hydrogen, nitrogen and sulfur from tool steel during vacuum degassing. Ironmaking \& Steelmaking. 2013;40(3):199-205.

5. Pretorius EB, Oltmann HG, Schart BT. An overview of steel cleanliness from an industry perspective. In: AISTech Proceedings; 2013 May 6-9; Pittsburgh, PA, USA. p. 993-1026.

6. Capurro C, Cerrutti G, Cicutti C. Effect of vacuum degassing on steel cleanliness. In: 9th International Conference and Exhibition on Clean Steel; 2015 Sep 8-10; Budapest, Hungary.

7. Capurro C, Cerrutti G, Cicutti C, Liz C, Bilancieri A, Traini P. Effect of vacuum treatment on liquid steel inclusion population. In: $20^{\text {th }}$ IAS Steel Conference; 2014 Nov 4-6; Rosário, Argentina. p. $60-70$.

8. Kang Y. Some aspects of non-metallic inclusions during vacuum degassing in ladle treatment with emphasize on liquid $\mathrm{CaO}$ $\mathrm{Al}_{2} \mathrm{O}_{3}$ inclusions. [Thesis]. Stockholm: KHT Royal Institute of Technology: 2007

9. Kang YJ, Nzotta M, Sichen D. Non-metallic inclusions and their distribution in the ladle before and after vacuum treatment of tool steel. Steel Grips. 2007;5:18-26

10. Steneholm K, Andersson M, Jönsson P. Change of Inclusion Characteristics during Vacuum Degassing of Tool Steel. Steel Research International. 2006;77(6):392-400.

11. Steneholm K, Andersson M, Nzotta M, Jönsson P. Effect of Top Slag Composition on Inclusion Characteristics during Vacuum Degassing of tool Steel. Steel Research International. 2007;78(7):522-530.

12. Médioni C. Influence of Stirring on the Inclusion Characteristics during Vacuum Degassing In a Ladle. [Licentiate thesis]. Stockholm: Royal Institute of Technology; 2014.

13. Rocha VC, Pereira JAM, Yoshioka A, Bielefeldt WV, Vilela ACF. Evaluation of Secondary Steelmaking Slags and Their Relation with Steel Cleanliness. Metallurgical and Materials Transactions B. 2017;48(3):1423-1432.

14. Reis BH, Bielefeldt WV, Vilela ACF. Absorption of non-metallic inclusions by steelmaking slags-a review. Journal of Materials and Research Technology. 2014;3(2):179-185.

15. Reis BH, Bielefeldt WV, Vilela ACF. Efficiency of Inclusion Absorption by Slags during Secondary Refining of Steel. ISIJ International. 2014;54(7):1584-1591.

16. Avillez RR, Costa e Silva ALV, Beneduce Neto F, Moraes CAM. Rede de termodinâmica computacional: inclusões em aços. Tecnologia em Metalurgia e Materiais. 2006;3(2):24-28.

17. Bielefeldt WV, Vilela ACF. Thermodynamics analysis of the inclusions formation in steels for the automotive industry. In: XL Calphad - Computer Coupling of Phase Diagrams and Thermochemistry; 2011 May 22-27; Rio de Janeiro, RJ, Brazil.

18. Bartosiaki BG, Pereira JAM, Bielefeldt WV, Vilela ACF. Assessment of inclusion analysis via manual and automated SEM and total oxygen content of steel. Journal of Materials Research and Technology. 2015;4(3):235-240.

19. Chen S, Wang X, He X, Wang W, Jiang M. Industrial Application of Desulfurization Using Low Basicity Refining Slag in Tire Cord Steel. Journal of Iron and Steel Research International. 2013;20(1):26-33.
20. Yang W, Zhang Y, Zhang L, Duan H, Wang L. Population Evolution of Oxide Inclusions in Ti-stabilized Ultra-low Carbon Steels after Deoxidation. Journal of Iron and Steel Research International. 2015;22(12):1069-1077.

21. Bielefeldt WV, Vilela ACF. Study of Inclusions in High Sulfur, Al-Killed Ca-Treated Steel via Experiments and Thermodynamic Calculations. Steel Research International. 2015;86(4):375-385.

22. Turkdogan ET. Fundamentals of Steelmaking. $2^{\text {nd }}$ ed. London: The Institute of Materials; 1996. $331 \mathrm{p}$.

23. Doostmohammadi H, Andersson M, Karasev A, Jönsson PG. Use of Computational Thermodynamic Calculations in Studying the Slag/Steel Equilibrium during Vacuum Degassing. Steel Research International. 2010; 81(1):31-39.

24. Bale CW, Bélisle E, Chartrand P, Decterov SA, Eriksson G, Hack K, et al. FactSage thermochemical software and databases - recent developments. Calphad. 2009;33(2):295-311.

25. Roscoe R. The viscosity of suspensions of rigid spheres. British Journal of Applied Physics. 1952;3(8):267-269.

26. Rocha VC. Viscosidade efetiva de escórias e parâmetro cinético de agitação aplicados na limpeza inclusionária de aços especiais durante desgaseificação a vácuo. [Dissertation]. Porto Alegre: Universidade Federal do Rio Grande do Sul; 2016.

27. Pistorius C. Bubbles in Process Metallurgy. In: Seetharaman S, McLean A, Guthrie R, Sridhar S, eds. Treatise on Process Metallurgy: Process Phenomena, Vol. 2. Amsterdam: Elsevier; 2014. p. 179-196.

28. Riboud P, Vasse R. Désulfuration de l'acier em poche: synthèse des résultats théoriques et industriels. Revue de Métallurgie. 1985;82(11):801-810.

29. Capurro C, Cerrutti G, Cicutti C. Study of the generation and modification of spinel type inclusions during secondary metallurgy and casting stages. In: $19^{\text {th }}$ IAS Steelmaking Conference; 2013 Nov 5-7; Rosário, Argentina. p. 332-341.

30. Singh U, Anapagaddi R, Mangal S, Padmanabhan KA, Singh AK. Multiphase Modeling of Bottom-Stirred Ladle for Prediction of Slag-Steel Interface and Estimation of Desulfurization Behavior. Metallurgical and Materials Transactions B. 2016;47(3):18041816.

31. Mendez J, Gomez A, Donayo R, Cicutti C. Effect of process conditions on the evolution of $\mathrm{MgO}$ content of inclusions during the production of calcium treated, aluminum killed steels. In: $8^{\text {th }}$ International Conference on Clean Steel; 2012 May 14-16; Budapest, Hungary.

32. Fruehan RJ, Pistorius C. Applications. In: Seetharaman S, McLean A, Guthrie R, Sridhar S, eds. Treatise on Process Metallurgy: Process Phenomena, Vol. 2. Amsterdam: Elsevier; 2014. p. $217-239$.

33. Zhang G, Chou K. Deoxidation of Molten Steel by Aluminum. Journal of Iron and Steel Research, International. 2015;22(10):905908.

34. Payandeh Y, Soltanieh M. Oxide Inclusions at Different Steps of Steel Production. Journal of Iron and Steel Research, International. 2007;14(5):39-46. 
35. Beskow K, Triphathi NN, Nzotta M, Sandberg A, Sichen D. Impact of slag refractory lining reactions on the formation of inclusions in steel. In: VII International Conference on Molten Slags, Fluxes and Salts; 2004 Jan 25-28; Cape Town, South Africa. p. 321-326.

36. Fruehan RJ. The Making, Shaping and Treating of Steel Steelmaking and Refining. $11^{\text {th }}$ ed. Pittsburgh: The AISE Steel Foundation; 1998.

37. Alexis J, Andersson M, Björkvall J, Sichen D, Sandberg A. JK Technical Report D 836. Optimization of secondary metallurgy with respect to non-metallic inclusions. Stockholm: Jernkontoret; 2011.
38. Song M, Nzotta M, Sichen D. Effect of ladle slag of previous heat on number of non-metallic inclusions in ladle treatment of tool steel. Ironmaking \& Steelmaking. 2011;38(8):584-589.

39. Jiang M, Wang XH, Wang WJ. Study on refining slags targeting high cleanliness and lower melting temperature inclusions in Al-killed steel. Ironmaking \& Steelmaking. 2012;39(1):20-25.

40. Choi JY, Lee HG, Kim JS. Dissolution Rate of $\mathrm{Al}_{2} \mathrm{O}_{3}$ into Molten $\mathrm{CaO}-\mathrm{SiO}_{2}-\mathrm{Al}_{2} \mathrm{O}_{3}$ Slags. ISIJ International. 2002;42(8):852-860.

41. Zhang L, Thomas BG. State of the Art in Evaluation and Control of Steel Cleanliness. ISIJ International. 2003;43(3):271-291. 